\title{
The Necessity Analysis for Economic Loss Evaluation of Traffic Accidents Considering the Needs of Different Groups of Users
}

\author{
Zhaohui LIU ${ }^{1}$ and Anna MIKHALCHENKO² \\ ${ }^{1}$ College of Transportation, Shandong University of Science and Technology, Qingdao, China \\ ${ }^{2}$ College of Transportation, Shandong University of Science and Technology, Qingdao, China and \\ T.F. Gorbachev Kuzbass State Technical University, Kemerovo, Russia
}

Correspondence should be addressed to: MIHALCHENKO Anna; gannamik@yandex.ru

Received date: 28 January 2019; Accepted date:26 April 2019; Published date: 2 July 2019.

Academic Editor: Yaseen Ahmed Meenai

Copyright (C) 2019. Zhaohui LIU and Anna MIKHALCHENKO . Distributed under Creative Commons CC-BY 4.0

\begin{abstract}
The article analyzes the methodological approaches to the assessment of economic losses from road traffic accidents, including in terms of meeting the needs of the main groups of users of these methods. The results of the study showed that in the developed countries of the world different approaches to assessing the cost of damage from road accidents are used. Different methodological approaches determine the receipt of different and, in most cases, completely incomparable results, which indicates the lack of operationality of the calculation methods used. In addition, the applied technologies for calculating economic losses from road accidents do not take into account the specific needs of different groups of users of these methods, which determines the high relevance of the development for the practical use of special methods for calculating damage that meet the expectations and requirements of their consumers.
\end{abstract}

Keywords: road accidents, economic losses, damage assessment, operational definition, methods

\section{Introduction}

Modern transport is the most important component of the world economy and has a huge impact on the dynamics of economic processes.
Approximately 1.2 million people die every year in road traffic accidents (RTA), and up to 50 million people are injured and become disabled. According to the World Bank, the annual economic damage from road traffic accidents reaches astronomical values, up to exceeds $\$ 500$ billion US dollars / year, taking into account the 
complex trends in the development of transport systems, there is every reason to believe that this is far from the limit.

A significant number of research papers are devoted to the problem of improving road safety. The work of scientists in the United States, Canada and the UK formed the basis of these studies. Until recently, research on road safety has focused on specific issues of probabilistic-statistical analysis of accident data, the development of road traffic accident models and specific activities aimed at achieving a predetermined goal.

In the modern period, due to the rapid development of transport logistics, the relevance of effective planning and management in transport and, in particular, the study of issues related to the assessment of the economic consequences of accidents has increased.

Knowing the cost of damage allows us to objectively assess the significance of the accident problem, determine the amount of financial and material resources that need to be invested in its solution, and evaluate the effectiveness of various measures contributing to the reduction of accidents.

The cost estimate of road traffic accident losses and bringing this information to the public have a powerful social and psychological effect and warn people about the threat to their life and health, help them understand the importance of road safety measures and create public support for their implementation.

Main methodological approaches to assessing the socio-economic damage from road accidents are presented below, which are currently used in world practice.

1. Theoretical approach based on the estimation of the person's average life cost (PALC).

The essence point of the approach: the human life cost is equal to the cost of its maintenance throughout the entire life cycle of the average person from birth to death.

It is made up of the cost of maintaining a child in a preschool, school, university, the expenses of a person to maintain his or her vital activities (food, dwelling, clothing, rest, cultural leisure), for treatment (buying medicines), raising children, etc., and payments of federal and municipal authorities (state expenditures) are calculated as the equivalent of funds spent on average for ensuring the life cycle of an individual from 0 years to life expectancy, regardless of his or her age.

2. Theoretical approach based on the theory of human capital (THC).

The main point of the approach: the value of human life is equal to the net present value of the benefits that other people (spouse, dependent people, partners, employers) could reasonably expect from future efforts of the individual whose life is being evaluated.

It is calculated as the sum of the means that a person could earn, if would live till the end of the working age, and the amount of retirement benefits that an individual could receive, if reached the average life expectancy in the region. The "human capital" approach is used to estimate the value of the lost production potential of a deceased or injured person as a result of an accident.

3. Theoretical approach, based on the subjective estimation of the human life value (SEHLV)

The main point of the approach: the cost of human life is estimated by the method of direct population survey.

The information about the willingness to pay for quality of life and public safety improvement is collected through surveys of the population or by studying the individuals' behavioral attitudes about their willingness to pay to minimize the risks of death or injury from traffic accidents. The last one is assessed using answers to questions about hypothetical situations in which the respondent was asked to assess the desirability of purchasing and using certain technical means of a personal vehicle safety to save life and health in traffic accidents. The approach is used to estimate the value of the lost quality of life.

Based on these approaches, in developed countries practical methods for calculating road traffic losses from traffic accidents were developed. They are reviewed below.

US transport police realizes the model to calculate the socio-economic damage caused by traffic accidents: (Theoretical approach, based on the theory of human capital (THC) + Theoretical approach, based on the subjective 
estimation of the human life value (SEHLV) + cost of external damage).

In this case, the calculation includes:

- the cost of direct damage (medical costs, administrative costs, market losses, nonmarket losses, insurance costs, costs of the hiring organization, legal costs);

- the cost of external damage (the cost of environmental damage, the value of property damage);

- the cost of subjectively assessed damage (the cost of life quality reducing).

The transport police of Canada implement the model to calculate the socio-economic damage caused by traffic accidents: (the THC approach + the SEHLV approach).

In this case, the calculation includes:

- direct economic costs (property damage, administrative costs, medical costs, legal costs, the cost of environmental damage, market losses);

- the amount of lost profits;

- the moral and physical suffering cost;

- a subjective assessment of the cost of human life and the willingness of the population to pay to minimize the traffic accidents risks.
The Australian transport police implements the model to calculate the socio-economic damage caused by traffic accidents: (the THC approach + the SEHLV approach).

In this case, the calculation takes into account:

- labor productivity loss;

- non-economic losses;

- non-monetary losses (moral damage value);

- the cost of damage from disability;

- insurance costs;

- medical expenses;

- legal costs;

- costs for calling police / ambulance to the scene of an accident

- cost of job loss risks;

- expenses for the re-qualification of the victim;

- expenses for ritual services and police investigation in case of death of the victim.

As can be seen from the above, economically developed countries of the world use different methodological approaches to assessing damage costs from road traffic accidents.

Table 1 presents estimates of economic damage from road traffic accidents, the transport police of various countries of the world reported.

Table 1: Estimation of the economic cost of damage from road traffic accidents, recorded by the transport police services in various number countries of the world

\begin{tabular}{|l|c|c|c|c|}
\hline № & Country & $\begin{array}{c}\text { Damage from } \\
\text { the road traffic } \\
\text { accidents, } \\
\text { billion \$ (2012) }\end{array}$ & GDP, billion \$ (2012) & \% of GDP \\
\hline 1 & Australia & 15,4 & 1014 & 1,52 \\
\hline 2 & Austria & 14,1 & 370 & 3,81 \\
\hline 3 & Belgium & 17,4 & 3443 & 3,88 \\
\hline 4 & Germany & 43 & 774 & 2,01 \\
\hline 5 & Netherlands & 15,6 & 144 & 1,92 \\
\hline 6 & New Zealand & 2,8 & 403 & 0,19 \\
\hline 7 & Singapore & 0,8 & 418 & 2,64 \\
\hline 8 & Switzerland & 11 & 2247 & 1,05 \\
\hline 9 & Great Britain & 23,5 & & 443 \\
\hline
\end{tabular}




\begin{tabular}{|l|l|l|l|r|}
\hline 10 & USA & 557,7 & 16163 & 3,45 \\
\hline \multicolumn{3}{|c|}{ Average } & 2,17 \\
\hline
\end{tabular}

Based on the data above, it can be concluded that in world practice a large number of approaches and, accordingly, techniques are used to estimate damage from traffic accidents. As a result, the indicators of economic damage from traffic accidents in different countries varies in a wide range, both in indicators pointing to the economic damage from traffic accidents in general, and in range of the damage cost from human death in gross domestic product of the country.

In this regard, there are some issues: what purpose is being pursued by the developers of the technique for damage estimations of traffic accidents; on the basis of which principles these techniques should be developed; how they should be evaluated, compared and selected.

To answer the above questions it is necessary, first of all, to structure the analyzed methods. As authors of this paper consider it is appropriate to use the concept of operational definition (OD) for this purpose.

\section{Theory}

For the first time this concept was introduced by Percy Bridgman back in 1927, in his work "The logic of modern physics", and later it became widely used in the scientific community not only in technical sciences, but also in the humanities.

In particular, this concept is fundamental within the framework of modern management methodology based on total quality management (TQM), the methodology of managing aimed at meeting customer expectations.

Within the framework of this concept, the interaction in management processes is required to consider from the point of view of efficiency of communications and quality of information exchange. Many recognized researchers noted that low quality of management, risk and significant harm in many cases are associated with not clearly defined basic concepts, criteria used by the participants in the different types of business and social interactions. Operational definitions (OD) of the concepts used should be applied to address or mitigate these losses and risks.

The operational definition of the indicator, requirements or characteristics consists of three parts.

1. Purpose of the indicator, requirements or characteristics, i.e. scope of its use.

2. Method of calculation, assessment of the indicator, requirements or characteristics. The procedure for obtaining an assessment should be clearly defined and described. This procedure (originally - "measurement operation", from where the term comes "operational definition") must meet the following requirements: interpreted;

- clear, understandable, unambiguously

- the results at the output of this procedure have the property of statistical stability;

- economically feasible (costs for implementation of procedure are justified from the point of view of the losses and risks eliminated as a result of use of OD).

3. Rule for decision-making based on the resulting measurement/evaluation procedure.

When following the principle of operational definition, in the process of analysis of any technique, it is necessary to answer the questions arising from the structure of OD:

- who uses estimates of damage from traffic accidents? Or, in terms of TQM, who is the consumer(s) of these estimates? To solve what kind of problems do these consumers use damage estimates? Under what kind of situations?

- how clear, understandable, unambiguously interpreted is the description of the methodology? How expensive is it, time-consuming? Does it give reproducible results, regardless of who uses it, in what kind of situations?

- what decision does the consumer make on the basis of the obtained estimates? 
- what additional requirements does the consumer make to the methodology of obtaining estimates based on the characteristics of the situation, the scope of the methodology and the nature of decisions taken on the basis of the received estimates?

Answer to the questions makes it possible to bring problem of analysis of estimation techniques from damage in traffic accidents to analyze their compliance with the goals and objectives of different types of consumers.

\section{Results and Discussion}

In this study, the following three main groups of consumers of accident damage assessment methodologies were identified.

1. Insurance company. These data are used to parameterize risk assessment models to determine economically feasible insurance rates; to assess damage in insurance cases.

2. Road designers, who use data from losses of traffic accidents to assess the appropriate level of investment in technical solutions to prevent accidents.
3. Authorities, who use data from losses of traffic accidents to assess the effectiveness of measures aimed at preventing/reducing the demographic, social and economic damage caused by traffic accidents, within the framework of the long-term and medium-term strategy of socio-economic development of the country and regions.

It is obvious that each of these groups of consumers puts forward different criteria requirements for methods of damage assessment.

Table 2 shows an example of highlighting the requirements of these groups of consumers to the methods for damage assessment of traffic accidents. The table in numerical form shows the importance of specific requirements (in points) for a certain type of consumer, established by the method of expert evaluations.

Under the table is the interpretation of the quantitative values used to assess the degree of importance / relevance of the requirements for a particular type of consumer.

Table 2: The requirements of different groups of consumers to the method for determining damage from traffic accidents

\begin{tabular}{|c|c|c|c|c|}
\hline & \multirow{2}{*}{$\begin{array}{l}\text { Requirements to the method for determining } \\
\text { damage from traffic accident }\end{array}$} & \multicolumn{3}{|c|}{ Consumers (users) } \\
\hline & & $\begin{array}{l}\text { Insurance } \\
\text { companies }\end{array}$ & $\begin{array}{c}\text { Road } \\
\text { designers }\end{array}$ & $\begin{array}{c}\text { Public } \\
\text { authority }\end{array}$ \\
\hline 1 & $\begin{array}{l}\text { Clarity, clarification, unambiguity of interpretation } \\
\text { of all steps of the methodology }\end{array}$ & 5 & 4 & 3 \\
\hline 2 & $\begin{array}{l}\text { The complexity of the methodology when it is used } \\
\text { to obtain damage estimates }\end{array}$ & 5 & 3 & 3 \\
\hline 3 & $\begin{array}{l}\text { The complexity of the method at the stage of } \\
\text { parameterization }\end{array}$ & 3 & 4 & 3 \\
\hline 4 & $\begin{array}{l}\text { The statistical stability of the methods, independent } \\
\text { of the person conducting the assessment }\end{array}$ & 4 & 3 & 3 \\
\hline 5 & $\begin{array}{c}\text { The completeness of accounting for long-term } \\
\text { damage factors (disclosed in other areas and over time) }\end{array}$ & 2 & 4 & 5 \\
\hline 6 & $\begin{array}{l}\text { The completeness of the immediate factors of the } \\
\text { damage }\end{array}$ & 5 & 4 & 3 \\
\hline 7 & $\begin{array}{l}\text { The possibility of documentary, legally relevant } \\
\text { factors fixation of the damage and confirmation of the level } \\
\text { of damage }\end{array}$ & 5 & 2 & 2 \\
\hline 8 & $\begin{array}{c}\text { Ability to obtain rapid / relevant damage } \\
\text { assessment }\end{array}$ & 5 & 3 & 2 \\
\hline 9 & $\begin{array}{l}\text { The possibility of using the technique without } \\
\text { attracting highly qualified staff who had special training }\end{array}$ & 4 & 4 & 2 \\
\hline 10 & $\begin{array}{l}\text { Robustness of the method - stability / sensitivity of } \\
\text { the values of the parameters used in the calculation to } \\
\text { changes in the socio-economic environment }\end{array}$ & 5 & 3 & 5 \\
\hline
\end{tabular}


Note. In table 2 the following significance rating scale is used:

1 - has no value to the consumer

2 - minimal, rather formal significance

3 - at the level of minimum sufficiency

4 - significant

5 - critically important.
Figure 1 shows the information from table 2 for clarity, which is presented in the format of a petal chart.

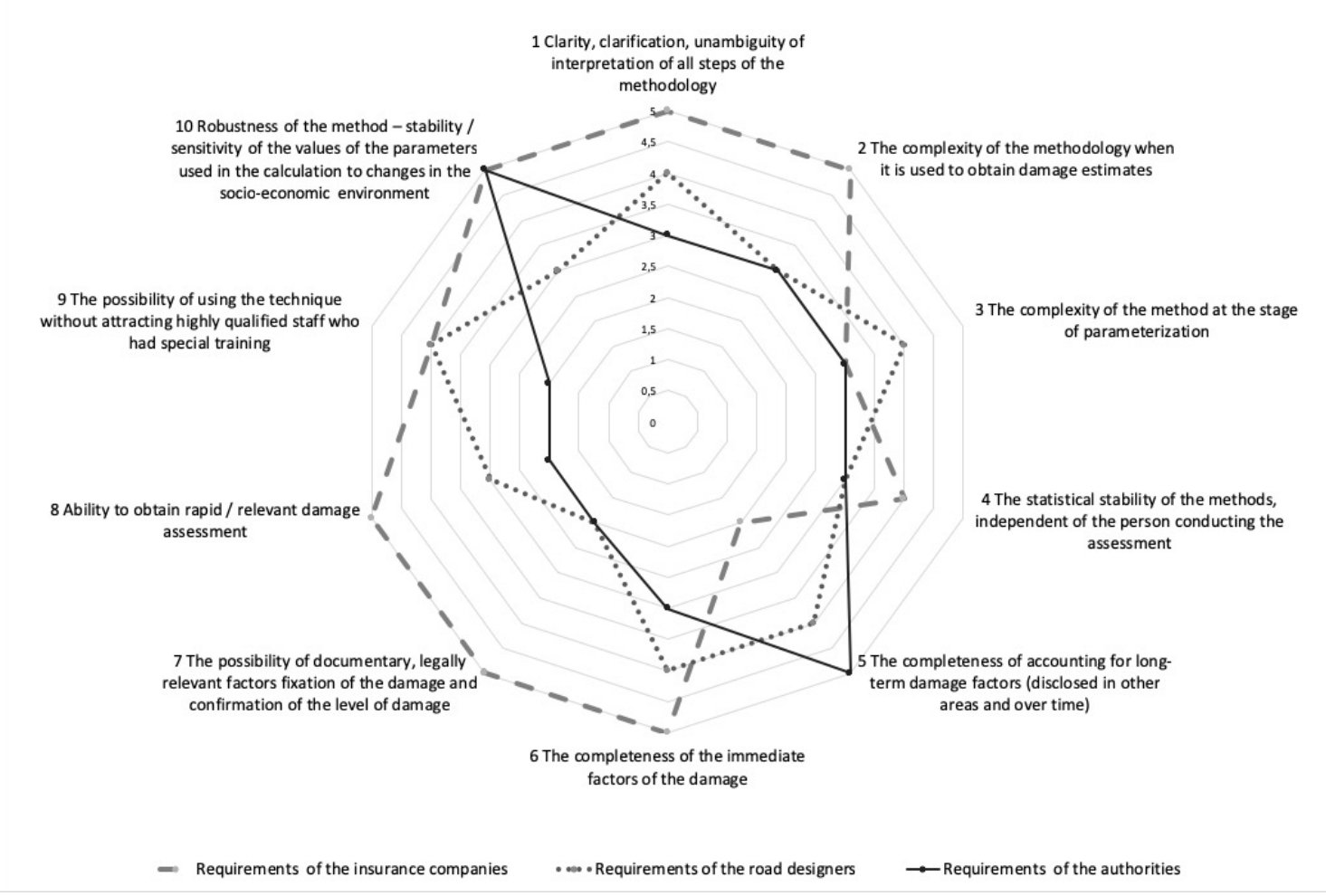

Figure 1: Comparison of requirements to evaluation methods that apply to different consumer groups

Structuring of requirements to methods in the form of table 2 / figure 1 provides an opportunity for a meaningful assessment of the methodologies in terms of their compliance with the requirements of different consumer groups.

As can be seen from the above diagram, the requirements of individual user groups for the method of determining damage from a traffic accident are fundamentally different.

\section{Conclusion}

To the present period of time in world practice certain generally accepted approaches to the analysis of data characterizing the state of road safety issues (road safety) have been established.

The first group of indicators is indicators that characterize the state of road traffic through the fixation of statistical data on the total number and severity of accidents.

The second group of indicators, used, as a rule, in evaluating the effectiveness of road safety programs are indicators of economic losses in road accidents, where the most significant component is the valuation of human life.

However, as shown by the results of the study in developed countries, various approaches are used to assess the cost of damage from road traffic accidents. Different methodological approaches predetermine obtaining different and completely disparate results. In addition, the resulting economic estimates of damage from road accidents are significantly "noisy" by a large number of various factors and, for example, for OECD member countries (Organization for Economic Cooperation and 
Development) the cost of human life is in the range of 1 million euros (Central and Eastern Europe) up to 4.5 million euros (USA, UK, Netherlands).

To this should also be added the fact that the applied technologies for calculating the economic losses from accidents do not take into account the specific needs of various groups of users of these methods. The root of this problem is the neglect of operational definitions when developing these methods. In this regard, it is appropriate here to give a figurative expression of U.E. Deming, the founder of philosophy and methodology of total quality management (TQM): "There are no absolute values, any parameter depends on the counting method, and if the method is changed, then the parameter will change ".

Thus, the results of the analysis show that the methods of analysis that are widely used in world practice sufficiently characterize the state of road safety issues, i.e. they are methods that fix the state of the issue, but they do not reveal the causal factors of accidents and are not a tool pointing the researcher to the direction of finding solutions to prevent accidents and, as a result, minimizing the economic losses from road accidents.

The foregoing determines the high relevance of the development for the practical use of special methods for calculating damage from road accidents that meets the expectations and requirements of the consumers of these methods.

\section{References}

1. Assessment of socio-economic damage from road accidents in Russia: methodological issues in the context of foreign research / Higher School of Economics, Moscow. (2015).

2. Bridgman P. The logic of modern physics. Beaufort Books. (1927).

3. Bureau of Infrastructure, Transport and Regional Economics. Impact of road trauma and measures to improve outcomes. Report 140 . (2014).

4. Deming, W.E. Out of the Crisis. Cambridge, MA: Massachusetts Institute of Technology, Center for Advanced Engineering Study. (1982)

5. Deming, W.E. Seminar on Quality, Productivity and Competitive Position, Student Notebook, Los Angeles, CA: Quality Enhancement Seminars, Inc. (1993).

6. Hill J., Starrs C. Saving Lives, Saving Money. The costs and benefits of achieving safe roads. (2011).

7. Jones-Lee M., Spackman M. The development of road and rail transport. (2013).

8. Pitel S., Solomon R. Estimating the number and cost of impairment related traffic crashes in Canada: 1999 to 2010. (2013).

9. Polozkov M.G., Ablaliev S.A., Sakanov D. K., Aspanbetov D. K. Methodological peculiarities of evaluation economic loss from road traffic accidents // Economics and modern management: theory and practice: Sat. Art. on mater. LXIII-LXIV Intern. scientific-practical conf. No. 7-8 (60). - Novosibirsk: SibAK, (2016).

10. The economic impact of motor vehicle crashes. National highway traffic safety administration. (2015). 